\begin{tabular}{ll} 
IJEMR & International Journal of \\
\hline & Emerging Multidisciplinary Research
\end{tabular}

\title{
Research on the Influencing Factors of Online Information Sharing Behavior in Social Media Circle
}

\author{
Hong Jin ${ }^{1}$, Ying Peng ${ }^{2}$, Seong-Taek, Park ${ }^{3 *}$ \\ ${ }^{1}$ School of Business, Jiangxi Normal University, Nanchang, JX 330000, China \\ ${ }^{2}$ School of Business, Jiangxi Normal University, Nanchang, JX 330000, China \\ ${ }^{3}$ Division of Software and Convergence, Sunmoon University, Asan, 31460, South Korea
}

\begin{abstract}
Background/Objectives: This paper analyzes the impact of social media circle characteristics on online information sharing behavior, and tries to provide proposals for improving the operation level of social media circle. Methods/Statistical analysis: The purpose of this study is to identify the preceding studies on Online Information Sharing Behavior in Social Media Circle and to establish a hypothesis through it. For this purpose, important factors were derived through previous studies. Findings: Through previous studies, important factors such as Relationship intensity, Number of members, Trust (Members' platform trust, Members' moral trust of others, members' ability trust of others), and online information sharing behavior were found and a research model was derived. Improvements/Applications: As this study is a qualitative study, it seems that a quantitative study is needed in the future.
\end{abstract}

\section{Index Terms}

Circle, influencing factors, online information sharing behavior, social media

\section{Corresponding author : Seong-Taek, Park}

solpherd@nate.com

- Manuscript received May 3, 2021.

- Revised May 19, 2021; Accepted May 27, 2021.

- Date of publication June 30, 2021.

(C) The Academic Society of Convergence Science Inc.

2546-1583 @ 2017 IJEMR. Personal use is permitted, but republication/redistribution requires IJEMR permission. 


\section{INTRODUCTION}

The popularity of mobile Internet makes every Internet user involved in social media networks more or less. Social media provides a platform for Internet users to find people like themselves. Internet users have gradually established their own circles on QQ, Wechat, microblog, twitter, Facebook, blog, BBS and other social media platforms.

In this circle, similar people, such as people with similar personalities or with the same goals, get together to communicate with each other, searching for information that works for them, and sharing their own information in the meanwhile.

The exchange and sharing of information is one of the most important functions of the social media circle for its members. Only through the continuous exchange of information can the social media circle survive [1].

However, more social media circles are facing the threat of disbandment due to the lack of content supply, which shows that it is of great significance to study the influencing factors of online information sharing behavior in social media circles[2-3].

However, at present, there are few studies on social media circles in academic circles. By analyzing the influencing factors of online information sharing behavior in social media circles, this study tries to provide suggestions for the operation of social media circles.

\section{LITERATURE REVIEW}

The convenience of the Internet makes every Internet user have the ability to upload and share information. At the same time, the Internet is efficient and not limited by time and space, so that every provider of information can share information with all other Internet users anytime and anywhere.

Therefore, online information sharing behavior has been studied in many fields, including sociality, psychology, communication, marketing and so on. Huang Lili and others define information sharing as the transmission of the information owned by individuals (including the original and forwarded information of the publisher) to others [4].

Zhang Liping and Wang Xingqiong also have a similar definition of the behavior of information sharing, that is, Internet users spread their own information to the outside world in a specific way with the help of the network platform based on a certain psychology [5].

The existing online information sharing behavior mainly focuses on the motivation and characteristics of this behavior, but pays less attention to the organizational basis of this behavior.

This paper focuses on the organizational perspective of social media circle to study the impact of circle characteristics on online information sharing behavior.

\section{THEORETICAL BASIS AND RESEARCH HYPOTHESIS}

Since ancient times in China, there has been a saying in China that "birds of a feather flock together, people are divided into groups", which shows that the ancient Chinese people have realized that there is a phenomenon that people with similar nature gather together in Chinese society, and this gathering group is the circle [6].

As one of the most common forms of organization, circle plays an important role in the behavior of its members. There is a clear boundary between the members of the circle and the individuals outside the circle, and there is often a stronger willingness to share information among the members of the circle than to share information with people outside the circle [7].

Sam's study found that groups with more emotionally intimate relationships were more closely connected [8]. This can be transferred to the organizational concept of circle, that is, the closer the relationship among the members of the circle, the more they are willing to share information online. Therefore, this paper puts forward the hypothesis:

H1: The relationship intensity in social media circles is positively correlated with online information sharing behavior.

The theory of network externality points out that the value of the network to the individual depends on the number of network members. The larger the number of members, the greater the value that the network brings to the individual [9].

Network externalities can directly increase the interests of consumers through the increase in the number of consumers in the network; in addition, the increase in the number of consumers in the network stimulates the emergence of complementary products in the network, which makes users more willing to use products in the network.

Lin and $\mathrm{Lu}$ introduced the network externality theory when studying the factors of people's continuous use of social networking sites, and found that the number of friends in social networks positively affects people's continuous participation behavior on social networking sites [10].

As a cluster of people with similar characteristics, the social media circle is quite similar to the social network, and the network externality theory also plays a role in the circle.

When there are a large number of members in the 
circle, the interaction between the members is stronger, and the willingness to search for information in the circle is also stronger, which inspires more members to participate in information sharing. Therefore, this paper puts forward the hypothesis:

H2: The number of members in the social media circle is positively related to online information sharing behavior.

Social relationships are built on the basis of trust, and social relationships cannot be maintained without trust [11].

In any modern society, due to the characteristics of complexity and uncertainty, individuals often lack sense of security when socializing, while trust can effectively reduce the complexity and uncertainty of social interaction and improve people's sense of security. Social interaction can be carried out normally 오류! 참조 원본을 찾을 수 없습니다.

According to previous research, in the social media circle, the trust of members mainly includes two dimensions: trust in the social media platform and trust in other members.

On the other hand, in the aspect of online information sharing behavior, the trust of circle individuals to other members includes the trust that they share information out of good motivation and the ability to provide correct information, that is, members' moral trust and member ability trust of others.

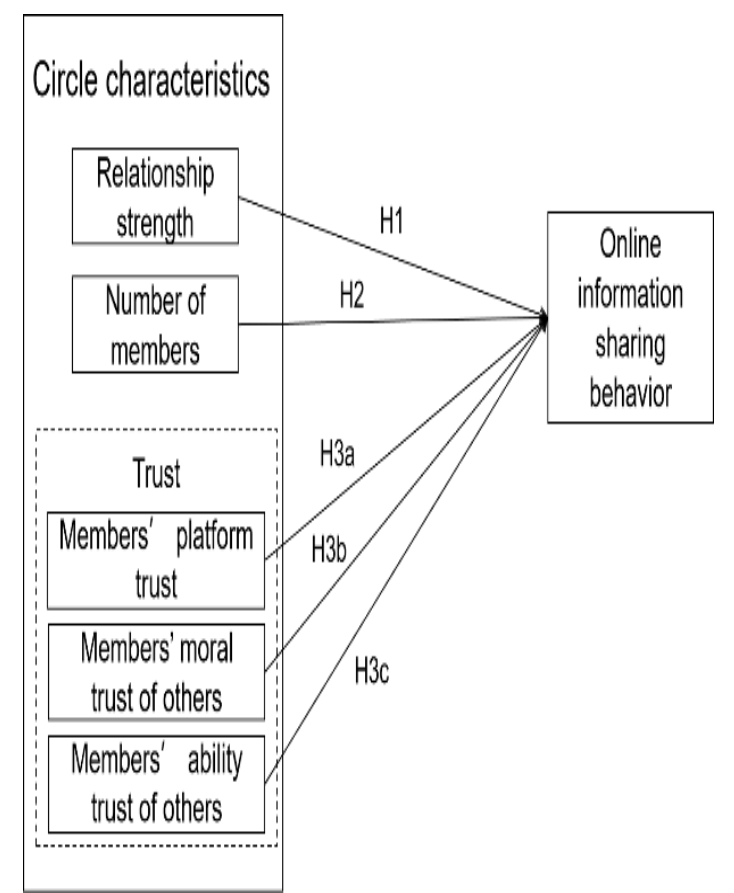

Fig. 1. Theoretical model.
Therefore, this paper puts forward the hypothesis:

H3a: Members' platform trust of the social media circle is positively correlated with the online information sharing behavior.

$H 3 b$ : Members' moral trust of others in the social media circle is positively correlated with the online information sharing behavior.

H3c: Members' ability trust of others in the social media circle is positively correlated with the online information sharing behavior.

\section{Conclusion}

Circle, as an important organizational basis in society, plays an invisible but important role in human behavior, but there is little research on this phenomenon at present.

This paper introduces this concept into the field of social media and analyzes the characteristics of the circle as the influencing factors of online information sharing behavior.

But obviously, the path from social media circle characteristics to online sharing behavior is more complex, and other influencing factors and pathways can continue to be explored in the follow-up research.

And this study only involves qualitative analysis, but this influencing factor and action path need to be tested by quantitative analysis in the future.

\section{REFERENCES}

[1] Sheng, Dongfang, \& Sun, Jianjun. (2016). A summary of foreign research on the influencing factors of knowledge sharing behavior in virtual community environment. Information Science, 34 (09), 166-172.

[2] Jin, H., He, C., \& Park, S.T. (2020). A Study on the Impact of Quantified-Self Awareness on Users' Information Sharing Behavior in the Mobile Social Network. International Journal of Emerging Multidisciplinary Research, 5(1), 15-19.

[3] Jin, H. \& Zhu, D. (2020). A Review of Information Seeking Behavior. International Journal of Emerging Multidisciplinary Research, 4(4), 8-10.

[4] Huang, Lili, Feng, Wenting, \& Qu, Xiangcheng. (2014). Factors affecting virtual community information sharing: multi-layer analysis perspective. International Press, 36 (09), 20-34.

[5] Zhang, Ziping, \& Wang, Xingqiong. (2018). A summary of the research on the behavior of network information sharing. Journal of Chongqing University of Science and Technology (Social Science Edition), 35 (05), 94-102.

[6] Wang, Rupeng. (2009). A brief discussion on circle culture. Academic Exchange, 2009 (11), 128-132.

[7] Li, Ping. (2015). Circle, face and competition: a theoretical Framework for analyzing Chinese knowledge sharing intention. Journal of China University of Geosciences (Social Science Edition), 15 (01), 120-131.

[8] Sam, G. B. R., \& Robin, I. M. D. (2011). Communication in social networks: effects of kinship, network size, and 
emotional closeness. Personal Relationships, 18(03), 439452.

[9] Katz, M. L., \& Shapiro, C. (1985). Network externalities, competition and compatibility. American Economic Review, $75,424-440$.

[10] Lin, K. Y., \& Lu, H. P. (2011). Why people use social networking sites: an empirical study integrating network externalities and motivation theory. Computers in Human Behavior, 27(3), 1152-1161.

[11] Peter, M. Brauer. (2008). Exchange and rights in social life. (Li, Guowu, Trans.). Beijing: commercial Press, 2008, 155.

[12] Nicholas Luman. (2005). Trust: a simplified mechanism of social complexity. (Qu, Tiepeng \& Li Qiang, Trans.). Shanghai: Shanghai century publishing group, 30-40. 